\title{
REVISÑO
}

\section{DIMENSÃO HISTÓRICA DAS EPIDEMIAS}

\section{Celina Maria Turchi Martelli ${ }^{1}$}

Este meu gosto de museus e pedras velhas, que no parecer de alguns denunciaria uma suspeita tendência para evasões, é, pelo contrário, o sinal mais certo de uma viva radicação no mundo em que estou. De facto, não creio que alguém possa, com verdade, dizer-se do seu tempo, se não se sentir envolvido num todo geral que abarque o mundo como ele é e como ele foi. (Saramago, 1996)

\section{RESUMO}

O artigo aborda as epidemias de varíola e cólera dentro do contexto histórico, com ênfase no pensamento dominante da época sobre a origem, difusão e mecanismos de controle. $\mathrm{O}$ intuito é fornecer alguns elementos de reflexão sobre as intervençð̋es médicas diante das epidemias em diferentes períodos. Discute-se, também, a complexidade das relaçð̃es ecológicas como potenciais indutoras de novas doenças infecciosas e a inadequação dos atuais sistemas de vigilância internacionais.

UNITERMOS: Epidemias. Historicidade. Doenças infecciosas.

\section{INTRODUÇÃO}

As epidemias, denominadas genericamente como pestes pelos antigos historiadores, são reconhecidos flagelos que atingem as comunidades desde os primórdios dos tempos, repercutindo no conjunto da população e acarretando mudanças nas sociedades. Desta forma, o impacto das epidemias deve ser interpretado dentro do contexto histórico em que se desenvolvem. A lista das epidemias de todos os períodos históricos é enorme e estima-se que elas tenham causado mais mortes, superando os óbitos ocorridos em decorrência de todas as guerras (Anderson \& May, 1991). Bastaria citar a

1 Professora Titular do Departamento de Medicina Tropical, Saúde Coletiva e Dermatologia IPTSP/UFG

Aula do Curso de História da Medicina, Faculdade de Medicina/ UFG, 1997

Recebido para publicação em 05/06/97

Vol. 26(1) 01-08. jan.-jun. 1997 
peste de Atenas (428 a.C.) que vitimou Péricles, a peste de Siracusa (396 a.C.) e a peste de Cos, célebre pelo relato segundo o qual todos os médicos foram infectados e morreram, quando se esforçavam em combatê-la (Durant, 1943).

Entretanto, a abordagem das "epidemias", como problemas de saúde pública, pautada na contagem dos casos de doença, taxas de adoecimento em nível populacional e intervenções em grande escala, aparece no século XVIII, período classificado pelos historiadores da saúde pública de "Moderna Estatística Sanitária" (Rosen, 1994). Nesta apresentação, abordaremos algumas epidemias no seu contexto histórico, com ênfase no pensamento dominante da época sobre a origem, a difusão e os mecanismos de controle. Nosso intuito é fornecer alguns elementos de reflexão sobre essas velhas e novas ameaças da humanidade.

\section{Abordagem das Epidemias na Antiguidade}

As epidemias, na Antigüidade, são conhecidas principalmente através dos historiadores e poetas, sendo difícil a interpretação dentro dos atuais paradigmas científicos. Convém lembrar que os sistemas filosóficos de compreensão do mundo dos povos da Antigüidade eram de caráter religioso. A Bíblia não inclui ensinamentos médicos, porém algumas moléstias são descritas como castigos vindos de Deus e, portanto, só por Deus poderiam ser curadas. Na história antiga, grega e romana, as doenças e, sobretudo, as pestilências eram também consideradas castigo dos deuses, daí a necessidade dos holocaustos, para aplacar a ira divina, e das preces públicas nos templos, para invocar proteção celeste. Em tempos de pestilências as descriçð̃es históricas revelam a aglomeração de pessoas nos santuários, enquanto as providências dos governos se resumiam apenas na queima dos cadáveres.

Os termos epidemia e endemia derivam do grego e, etimologicamente, significam aumento de doença em determinada população e doença originária de um país, respectivamente. No Corpus Hippocratium, livro dos ensinamentos do pai da medicina (Hipócrates, 460-380 a.C.) há sete livros com o título de Epidemias com descrições clínicas detalhadas de doenças infecciosas (Rezende, 1997). Galeno (161-205 d.C.), o mais célebre médico da antiguidade após Hipócrates, descreveu meticulosamente os sintomas da peste que assolou Roma: "os corpos dos áoentes eram sacudidos por tosse raivosa, enchiam-se de feridas e seu hálito fedia". Estima-se que só em Roma morreram mais de 200.000 pessoas em poucos meses, dizimando um quinto da população da época (Durant, 1943). A palavra endemia, com a conotação de doença referente a um determinado local, é atribuída a Galeno. Portanto, os termos epidemias e endemias estão entre os termos mais antigos em medicina (Rezende, 1997).

Na Idade Média, período de consolidação do modo de produção feudal, a medicina volta a se revestir, de forma dominante, da prática religiosa sob a influência do cristianismo. Por ser a idade da fé por excelência, desprezou a doutrina materialista de Epicuro e seguiu à risca a velha crença de que as epidemias eram castigo de Deus. Um Deus sempre invocado, tanto na esfera individual como na coletiva. A ciência não oferecia remédios para as doenças transmissíveis e havia um número crescente de epidemias. Por exemplo, a Peste Negra do século XIV, que tendo começado na Ásia Central, disseminou-se no Oriente e Ocidente. Estima-se que metade da população da Europa tenha sido por ela dizimada (Rosen, 1994).

Neste período, denominado Idade das Trevas, as epidemias associam-se não apenas a fenômenos sobrenaturais e castigos divinos, mas também à conjunção de certos planetas, ao envenenamento de poços por leprosos e judeus e às bruxarias. A prática da quarentena, como esforço de regulamentação para lidar com as epidemias, consistindo no isolamento dos doentes "contagiosos", deriva da Idade Média (Rosen, 1994; Plotkin \& Kimball, 1997), sob a inspiração dos ensinamentos bíblicos. O número quarenta é o número bíblico da provação, considerado número arquétipo e cabalístico: Jesus permaneceu quarenta dias no deserto; os hebreus vagaram durante quarenta anos entre o Egito e a Terra Prometida; o dilúvio foi provocado por uma chuva de quarenta dias; no Levítico (12:2 1 5), a purificação de parturientes se processava em 40 dias, quando davam à luz um menino e, se fosse menina, seria de duas vezes 40 . Também no tantrismo budista, o "serviço" da mulher está dividido em provações de 40 dias. A quarentena, enquanto intervenção de saúde pública, permanece até os dias atuais, embora o tempo de isolamento seja estabelecido pelo período de transmissibilidade da doença sob investigação.

No Renascimento, e sobretudo a partir de século XVII, há um novo enfoque em todas as ciências e as explicações dos fenômenos baseiam-se em experimentos. Neste período a medicina volta a ser exercida por leigos. No entanto, a concepção dominante sobre o aparecimento e o desaparecimento das epidemias era a teoria miasmática, assim descrita por Sydeham:

Há diferentes constituiçðes em diferentes épocas. Elas não se originam nem do calor, nem do frio, nem da umidade, nem da secura, elas dependem de certas misteriosas e inexplicáveis alteraçð̃es nas entranhas da terra. Pelos seus eflúvios, a atmosfera tornase contaminada e os organismos dos homens são predispostos e determinados. (apud Rosen, 1994)

Essa enunciação sobre a origem das doenças e pestilências como causa vaga e inespecífica pode ser compreendida pela definição de Sydeham.

Durante todo o século XVIII, apesar do progresso intenso das ciências em geral, a teoria miasmática persiste hegemônica, enquanto explicação da origem das doenças contagiosas. A crescente urbanização dos países europeus no final do século XVIII, determinando um crescimento 
populacional e um novo sistema de produção, que consistiu na consolidação do sistema fabril na Inglaterra, deu origem à saúde pública da forma que nós a conhecemos hoje. Manchester, a primeira cidade industrial da Inglaterra, é acometida durante o inverno de 1795 de uma epidemia de tifo exantemático, o que mobiliza as autoridades à criação do Conselho de Saúde Voluntário. O cenário descrito para as cidades da época era de locais extremamente insalubres, sem nenhum planejamento urbano, com fábricas instaladas em qualquer local, acomodando-se os trabalhadores onde podiam, favorecendo, portanto, o aparecimento de epidemias (Thompson, 1987). Na área da medicina individual surgem os profissionais que se interessam por febres (febre tifóide, tifo, febre recorrente), talvez os precursores dos atuais infectologistas. A observação constante deste período é que a população trabalhadora não apenas era atingida de forma mais séria, mas que esses surtos ocasionavam perda econômica.

Ao término do século XVIII, estava enraizada na atenção pública a convicção de serem os problemas de saúde e doença fenômenos sociais de muita importância para o indivíduo e a comunidade. Há uma consciência da necessidade de intervenção do governo na saúde pública, em especial nos Estados de língua alemã, criando a Política médica e a Polícia médica para a vigilância sanitária (Rosen, 1994).

Varíola - a longa história de sua erradicação. A varíola era endêmica na Grã-Bretanha no século XVIII e constituía uma das principais causas de óbito entre crianças. A varíola era também considerada a principal causa de cegueira na Europa. Naquele período, destaca-se o experimento de Edward Jenner (1749-1823), médico rural inglês, que utilizou a pústula da mão de uma ordenhadora como inóculo para o procedimento de variolação. A publicação de Jenner, de 1789, intitulou-se Uma investigação sobre as causas $e$ os efeitos da vacina de variola, uma doença descoberta em alguns condados do oeste da Inglaterra, em particular Gloucestershire, e conhecida pelo nome de vacina. Jennifer refere-se ao material infeccioso utilizado no experimento como vaccine. Portanto, o termo vacina derivou do substantivo latino vacca. A descrição do primeiro experimento de Jenner foi recusada pela Sociedade Real, mas o sucesso da prática de vacinação foi imediato. Rapidamente se expandiu a idéia da variolação, estimando-se que, pelo menos, 100.000 pessoas teriam sido vacinadas só na Inglaterra poucos anos após a descoberta (Rosen, 1994; Henderson, 1997). Remonta a este período a origem histórica da imunização de massa, bem como os dispensários de vacinação pública. Hoje, a vacinação talvez seja a intervenção de saúde pública mais utilizada e efetiva para diferentes doenças em todo o mundo.

Apesar da aceitação inicial do uso da vacina, esta prática de saúde pública encontrou oposição por motivos religiosos, pois alguns líderes religiosos alegavam ser errado prevenir doenças que seriam mandadas por Deus. Outra objeção referia-se à dificuldade técnica de assegurar a integridade e a qualidade da vacina, além da contaminação da vacina com outros microorganismos. Também havia o argumento contra a vacinação compulsória sob a alegação de que representava uma violação da liberdade individual. Esta oposição no Brasil foi encabeçada por Rui Barbosa e a história dos embates políticos e da discussão ética sobre os direitos individuais e a intervenção do Estado é apresentada por Servenco (1984) e Chalhoulb (1996).

Apesar da descoberta da vacinação contra a varíola em 1796, o método de inoculação de braço para braço trazia riscos de transmissão de outras doenças, particularmente sífilis. Só após 1950 quando as questð̃es técnicas relativas à produção comercial em larga escala da vacina de varíola forami resolvidas, foi possível fazer um programa de erradicação com sucesso. Assim, a estratégia de vigilância em nível mundial é recente (1962), o que exigiu o compromisso de todos os países endêmicos, sob coordenação de organismos internacionais, como o Centers for Disease Control and Prevention (CDC) e Organização Mundial de Saúde (OMS), culminando com a erradicação da varíola na mundo (Hopkin, 1983; Fenner et al. 1988; Henderson, 1997).

As epidemias de cólera - antiga e atual. A situação de saneamento das cidades no século passado favorecia o aparecimento e a disseminação de epidemias. São bem descritas as epidemias de cólera de 1831 e 1832, em Londres. Os casos de cólera eram identificados nos distritos mais pobres da cidade, com nítida correlação com os locais onde mais se negligenciavam as medidas sanitárias, isto é, as áreas mais poluídas por excrementos e lixo. As doenças pestilenciais mobilizam a sociedade como um todo pelo perigo do contágio e pela disseminação da infecção para as classes mais privilegiadas. Aparece, dessa forma, a visão da classe média, empenhada em nova ética, em que predominam os conceitos de ordem e disciplina social e uma preocupação com as condições humanas. Estes conceitos estão embutidos nos movimentos de Revolução Industrial e Revolução Agrária (Rosen, 1994).

Como prenúncio dessa nova era, citamos John Snow (1813-1858) médico anestesista da rainha Vitória, considerado o pai da Epidemiologia. Seu estudo da epidemia de cólera de 1848 -Sobre a maneira de transmissão do cólera - notabilizou-o como epidemiologista. Realizou uma investigação sistemática do local onde ocorriam as mortes por cólera nas regióes sul de Londres, correlacionando-as com as duas principais companhias distribuidoras de água da época (Winkeslstein, 1995; Scliar, 1997). Pelas características clínicas da doença, inferiu que o "veneno" era um ser vivo específico, que entrava pelo canal alimentar diretamente pela boca, sendo oriundo da excreção dos próprios pacientes. Postulou, ainda, que a moléstia se transmitia de pessoa a pessoa, através das mãos sujas ou di alimentos e água contaminados, podendo os excrementos também contaminar o solo e a água. Estas deduções, que hoje parecem tão óbvias, eram verdadeiramente

Vol. 26(1) 01-08. jan.-jun. 1997 
revolucionárias, tanto do ponto de vista da compreensão da doença em nivel individual como de sua propagação e principalmente pela possibilidade de açбes de controle dentro da cadeia epidemiológica de eventos. Conta o folclore que o próprio Snow, convicto de sua teoria, destrói a bomba de fornecimento de água contaminada, intervindo diretamente na epidemia.

Descoberta dos agentes etiológicos. A era bacteriológica da saúde pública tem início em $1875 \mathrm{e}$, em duas décadas, praticamente todos os microorganismos passíveis de ser vistos através do microscópio óptico foram identificados e seus mecanismos de transmissão e disseminação foram elucidados, ampliando, assim, as perspectivas de controle. Este período de 1875 a 1950 compreende a idade de ouro das descobertas bacteriológicas (Rosen, 1994). Estas descobertas iriam modificar toda a prática médica individual e coletiva, pela introdução de novas tecnologias para exames laboratoriais, que resultaram na produção de medicamentos específicos contra microorganismos como os antibióticos, bem como na produção em escala industrial de vacinas. No entanto, apesar da identificação do Vibrio cholerae como agente etiológico do cólera, do conhecimento sobre sua disseminação e da experiência de inúmeras epidemias, mesmo assim diferentes pandemias de cólera ocorrem na Ásia e nas Américas ainda neste século (Wilson, 1995). Vale mencionar que, no continente americano, o cólera reaparece em proporçð̃es epidêmicas no início da década de 90 estabelecendo-se a sétima pandemia de cólera. A cepa $V$. cholerae $\mathrm{O} 1$, sorotipo Inaba, biotipo El Tor, indistinguível do asiático aparece no Golfo do México, sendo o comércio entre países imputado na disseminação deste agente. Em quatro anos estimam-se mais de 1 milhão de casos com 9.000 óbitos por cólera na América do Sul (OPS, 1995; OPS, 1996). Entre as consequências econômicas, estima-se que o Peru, um dos países mais atingidos, tenha tido um prejuízo da ordem de 700 milhões de dólares pelo embargo internacional no comércio e em intercâmbios de viagens.

As epidemias velhas e novas do século $X X$. Neste século surgem as epidemias de doenças crônicas e quando se pensava que as doenças infecciosas fossem doenças ultrapassadas, passíveis de serem controladas através de vacinas ou de remédios, surge, de forma explosiva e desconcertante, a pandemia da AIDS, denominada como a praga lenta do final do século (Gould, 1993). Com o primeiro caso em 1980, esta doença desconhecida atinge 193 países em 15 anos, portanto, configurando uma pandemia. As estimativas são assustadoras: um reservatório de 20 milhões de indivíduos infectados pelo HIV; dos 3 milhões de casos acumulados de AIDS nas Américas, 2 milhơes referem-se a habitantes da América Latina e Caribe; há tendência ao incremento de registros nas categorias de transmissão heterossexual e perinatal. Mais de 5 milhões de adultos e crianças morreram de AIDS no mundo nos últimos 5 anos (Quinn, 1996). Em muitas comunidades dos Estados Unidos a infeção pelo HIV é uma das principais causas de morte entre adultos jovens (Selik et al, 1993)

Inúmeras outras doenças infecciosas, como o cólera clássico na América do Sul e na África, doença de Lyme, o vírus Ebola, a encefalite espongiforme bovina, entre outras, continuam a desafiar o potencial de intervenção na saúde pública dentro do nosso complexo sistema social, exigindo respostas com coordenação interpaíses. Estas novas doenças infecciosas emergentes e reemergentes transformam a regulamentação internacional e nacional de quarentena em sistemas de vigilância obsoletos, exigindo novas estratégias globais para o controle (Plotkin \& Kimbalt, 1995; Morse, 1995; Marques, 1995; Fidler, 1996)

O espantoso desenvolvimento tecnológico da atualidade, com a aparente ilimitada disponibilidade de informação e intercâmbio científico interpaíses, bem como a compreensão dos mecanismos de transmissão em nível de estrutura molecular têm sido pouco eficientes não apenas para predizer o aparecimento de novas epidemias, bem como para planejar a interrupção das existentes. Mesmo nestes tempos de alta tecnologia, ressurgem em épocas de epidemias: o pânico dos agentes transmissíveis misteriosos, a invocação de castigo divino, idéias preconceituosas e presságios de catástrofes coletivas para justificar a discriminação de grupos mais acometidos e, por vezes, mais vulneráveis socialmente. A explicação mítica parece ser o elo invisível entre as velhas e novas epidemias, como parte do inconsciente coletivo desde os tempos imemoriais, como nos revelam os historiadores das velhas epidemias. A história das epidemias pode nos ajudar a refletir sobre o passado e o presente, embora a predição do futuro pareça um ideal distante pela complexidade das relações ecológicas como potenciais indutoras de novas doenças infecciosas e pelo imponderável das alterações da cultura humana.

\section{SUMMARY}

Historical dimensions of epidemics

The small pox and cholera epidemics are analyzed inside an historical context, with a highlight on how the control mechanisms, origin and spread of these diseases were understood at the time. The purpose was to provide some elements for reflections on medical interventions carried out on different periods of time facing epidemics. The complexity of ecological relationships as potential inductors of new transmittable diseases and the inefficiency of the present international surveillance systems are also discussed.

KEYWORDS: Epidemics. Hístory. Infectious diseases.

Vol. 26(1) 01-08. jan.jun. 1997 


\section{REFERÊNCIAS BIBLIOGRÁFICAS}

01.Anderson RM \& May RM. Infectious diseases of humans. Dymamics and controls. Oxford: Oxford University Press, 1991, p. 1-9.

02.Chalhoulb S. Cidade febril, cortiços e epidemias na corte imperial. Săo Paulo: Companhia das Letras, 1996.

03.Durant Will. História da civilização. Rio de Janeiro: Companhia Editora Universal, 1943.

04.Fenner F, Henderson DA, Arita I, Jesek Z, Ladnyi ID. Smallpox and its erradication. Geneva:World Health Organization, 1988.

05.Fidler DP. Globalization, international law and emerging infectious diseases. Emerging Infectious Diseases. 2:77-84, 1996.

06.Gould P. The slow plague: a geography of the AIDS epidemic. Oxford. Blackwell, 1993.

07.Henderson DA. Smallpox vaccine: Edward Jenner's vaccine. Public Health Reports, 112: 117-121, 1997.

08.Hopkins DR. Princes and peasants: smallpox in history. Chicago: University of Chicago Press, 1983.

09.Marques MB. Doenças infecciosas emergentes no reino da complexidade: Implicações para as políticas cientificas e tecnológicas. Cadernos de Saúde Pública, 11:361-388, 1995.

10.Morse SS. Factors in the emergence of infectious diseases. Emerging Infectious Disease, 1: 7$15,1995$.

11. Organizacion Panamericana de la Salud/OPS. Centros para el control y prevención de enfermidades de los Estados Unidos (CDC): 50 años, 17 (3), 1996.

12.Organizacion Panamericana de la Salud/OPS. Enfermidades infecciosas nuevas, emergentes y reemergentes. Boletin Epidemiológico, 16:1-7, 1995.

13.Plotkin BJ, Kimbalt AM. Designing an international policy and legal framework for the control of emerging infectious diseases: First steps. Emerging Infectious Diseases, 3: 1-9, 1997.

14.Quinn TC. Global burden of HIV pandemic. Lancet, 348:99-109, 1996.

15.Rezende, JM. Linguagem médica. São Paulo: Fundo Editorial BYK, 1997.

16.Rosen, G. Uma história da Saúde Pública. São Paulo: Unesp, Hucitec, Abrasco, 1994.

17.Saramago J. A bagagem do viajante. São Paulo: Companhia das Letras, p. 159, 1996.

18.Scliar, M. A paixão transformada: história da medicina na literatura. São Paulo: Cia das Letras, 1996.

19.Selik RM, Chu SY, Buehler JW . HIV infection as the leading cause of deaths among young adults in US cities and States. JAMA, 269:2991-2994, 1993.

20.Sevcenko, N. A revolta da vacina: mentes insanas em corpos rebeldes. Săo Paulo: Brasiliense, 1984.

21.Thompson, E.P. A formação da classe operária inglesa. I. A árvore da liberdade. São Paulo: Edit. Paz e Terra, 1987.

22.Wilkelstein WJ. A new perspective on John Snow's communicable disease theory. American Journal of Epidemiology, 142: S3-S9, 1995.

23.Wilson ME. Travel and the emergence of infectious diseases. Emerging Infectious Diseases, I: 1-7, 1995. 